\title{
LIXIVIAÇÃO E INATIVAÇÃO DO METRIBUZIN EM DOIS TIPOS DE SOLOS1
}

\section{J. Ferreira da SILVA*, J. Francisco da Silva** R.F. da SILVA** \& A.R. CONDÉ**}

* Professor Assistente da Universidade do Amazonas e Bolsista do CNPq - Departamento de Ciências Agrárias - Estrada do Contorno, s/n. ${ }^{\circ}$ 69.9C,0 - MANAUS-AM

** Professores Titulares da Universidade Federal de Viçosa. 37.570 - VIÇOSA-MG

(') Parte da tese apresentada à Universidade Fe deral de Viçosa, pelo primeiro autor, como parte das exigências para obtenção do grau de "Magister Scientiae" em Fitotecnia.

\section{RESUMO}

Com o objetivo de avaliar a lixiviação e a inativação do herbicida metribuzin (4-amino-6-tertbutil-3-(metiltio)-as-triazina-5-(4H)ona)

materiais de um solo franco-argiloso e de outro solo franco-argilo-arenoso de duas regiões de Minas Gerais, um em laboratório e outro em casa de vegetação. O solo franco-argiloso era um Latossolo Roxo, com 2,8\% de matéria orgãnica e o solo franco-argilo-arenoso era um Podzólico Vermelho-Amarelo; fase terraço, em 2,17\% de matéria orgânica.

Em laboratório estudou-se a lixiviação do metribuzin em colunas de 5,10 e $15 \mathrm{~cm}$ de altura, com $7,5 \mathrm{~cm}$ de diâmetro, enchidas com materiais dos solos franco-argiloso e do solo franco-argiloarenoso. Usou-se o ensaio biológico de discos de cotilédones de melancia para detectar o metribuzin no lixiviado.

Em casa de vegetação, estudou-se a inativação do metribuzin com materiais dos mesmos solos utilizados para o estudo de lixiviação. Para este ensaio foram utilizadas as doses de $0,50,80$, $110,140,170$ e $200 \mathrm{~g}$ do i.a./ha do produto, e em areia lavada, as doses foram de $0,4,6,8,10,12$ e $16 \mathrm{~g}$ do i.a./ha do metribuzin, usando o pepino como planta teste, que foi cortado rente ao solo e pesado aos 14 dias após o plantio.

Informações adicionais são necessárias para explicar porque o solo franco-argiloso inativa mais o met ibuzin que o solo franco-argilo-arenoso.

PALAVRAS CHAVE: metribuzin, lixiviação adsorção.

\section{SUMMARY}

LEACHING AND INACTIVATION OF METRIBUZIN IN TWO SOIL TYPES Laboratory and greenhouse experiments were made to evaluate the leaching and the inactiva- tion of the metribuzin in clay loam and sand clay loam soils. The clay loam soil was a dark, red latosol with $2,8 \%$ organic matter and the sand clay loam soil was a reddish-yellow podzol with $2,17 \%$ organic matter.

Leaching of metribuzin was studied in the laboratory in colums of 5,10 and $15 \mathrm{~cm}$ high, 7.5 $\mathrm{cm}$ diameter, filled with soil. Watermelon cotiledon discs were used to measure the metribuzin leached.

The inactivation of metribuzin was estudied in a greenhouse using doses of $0,50,80,110,140$, 170 and $200 \mathrm{~g} / \mathrm{ha}$ on the two soils, and $0,4,6,8,10$, 12 and $16 \mathrm{~g} / \mathrm{ha}$ were used for testing in sand. The test plants were cucumber that weighed after 14 days growth.

Additional information is needed to explain why the clay loam soil inactivates metribuzin more than the sand clay loam soil and clarify the roles.

KEYWORDS: metribuzin, leaching, inactiva tion

\section{INTRODUÇÃO}

O metribuzin (4-amino-6-tert-butil-3(metiltio)-as-triazina-5(4H)ona) é um produto novo e seletivo para as culturas de soja, tomate e batata e eficiente no controle de muitas espécies de plantas daninhas tais como:

Sida spp, Sesbania spp, Datura spp, as quais não são controladas pelos herbicidas tradicionalmente recomendados para aquelas culturas $(3,5)$. Trabalhos realizados no Brasil $(6,7,8)$ têm demonstrado problemas de fitotoxicidade à cultura de soja com o emprego de doses normalmente recomendadas 
nos Estados Unidos e em alguns países europeus (5). A diferença de tolerância ao produto aplicado no Brasil e naqueles países pode estar relacionado, entre outros fatores, com sua lixiviação e a inativação pelos coloides dos nossos solos.

A lixiviação do metribuzin em colunas de 5,10 e $15 \mathrm{~cm}$ de solos orgânico, franco-argiloso e arenoso, com 56,0, 2,0 e $0,2 \%$ de matéria orgânica, respectivamente, foi estudada por Silva (11). 0 autor relata que as percentagens de metribuzin lixiviada sobre a coluna de 5 $\mathrm{cm}$ foram 84,32 e $3 \%$ nos solos arenoso, franco-argiloso e orgânico, respectivamente. Esse autor, estudando a ads orção do metribuzin em areia de quartzo lavada e adicionada de $1 \%$ de caolita e/ou bentonita saturada com $\mathbf{H}^{+}$adsorveu mais metribuzin que a areia lavada, concluindo que a ads orção do metribuzin não é alterada por esses dois tipos de argila no solo. O mesmo autor trabalhando com areia e adicionada de 1 , 2, 4 e $8 \%$ de matéria orgânica, verificou que a adsorção do metribuzin aumentou linearmente com o aumento de matéria orgânica.

A lixiviação do metribuzin com 250 $\mathrm{mm}$ de água, em solo com $1,6 \%$ de matéria orgânica demonstrou que o com posto permaneceu nos $5 \mathrm{~cm}$ superficiais (4).

Os objetivos deste trabalho foram os de estudar a lixiviação e a inativação do metribuzin em diferentes tipos de solos.

\section{MATERIAIS E METODOS}

\section{Lixiviação do metribuzin}

Neste experimento, estudou-se em laboratório, a lixiviação do metribuzin em três diferentes alturas de colunas com materiais dos solos de Capinópolis-MG e de Ponte Nova-MG. As análises químicas e granulometricas, bem como a clas sificação textural dos solos, encontram-se nos quadros 1 e 2 , respectivamente.

Daqui para a frente os materiais dos solos de Capinópolis e de Ponte Nova serão citados pela sua classificação textural.

Colunas de tubo de PVC, de 7,5 $\mathrm{cm}$ de diâme tro, foram cortados em tamanhos de 7,$5 ; 12,5$ e $17,5 \mathrm{~cm}$ de altura. Na parte inferior de cada coluna colocou-se uma folha de papel filtro, e, por cima desta, um tecido ralo, que era preso à coluna por uma fita elástica. O solo foi colocado aos poucos e ligeiramente compactado até as alturas de 5,10 e $15 \mathrm{~cm}$, nas colunas de 7,$5 ; 12,5$ e $17,5 \mathrm{~cm}$, respectivamente.

As colunas montadas com materiais dos solos foram saturadas por sub-irrigacão com água destilada. As colunas eram retiradas da água e deixadas sobre os copos durante duas horas, para drenar o excesso de água, que era eliminado.

Após esse período, foram aplicados, na superficie de cada uma das colunas, $10 \mathrm{ml}$ de água com metribuzin, na proporção de $1 \mathrm{~kg}$ do i.a./ha, calculado em função da superfície da coluna.

Duas horas após a aplicação do herbicida, foi este lixiviado, usando-se um volume de $240 \mathrm{ml}$ de água, perfazendo um total de $250 \mathrm{ml}$, equivalente à precipitação de $56 \mathrm{~mm}$.

O volume do lixiviado, foi medido para pos terior determinação quantitativa do herbicida no lixiviado. Para detectar o herbicida lixiviado, foi usado o bioensaio de discos de cotilédones, descrito por Silva et ali (12).

Esse bioensaio consiste no uso de copos de $250 \mathrm{ml}$ com $100 \mathrm{ml}$ de uma solução- tampão de fosfato de potássio, $0, \mathrm{O} 1 \mathrm{M}$, com $\mathrm{pH}=6,5$, adicionada de $0,01 \%(\mathrm{~V} / \mathrm{V})$ de agente surfactante. Nesses copos são colocados discos de $6 \mathrm{~mm}$ de diâmetro de folhas cotiledonares de meláncia (Citrulus lanatus (Thunb.) Matsum e Nakai), cultivar Charleston Gray. Nessas condições, os discos flutuam em presença de luz e afundam no escuro.

Os tratamentos foram repetidos 4 vezes e o experimento 2 vezes.

\section{Inativação do metribuzin}

Este experimento foi instalado em casa-devegetação, usando o pepino (Cucumis sativus L.), variedade Marketer, como planta teste. Dez sementes foram plantadas em copos contendo areia lavada, e outras dez sementes foram plantadas em copos de plástico (104 cm de área média) que continham 500 gramas de solo franco-argilo ou franco-argilo-arenoso. As análises químicas e granulométricas bem como a classificação textural dos solos, encontram-se nos quadros 1 e 2 , respectivamente.

Foram incorporados à areia lavada as seguintes doses de metribuzin: $0,4,6,8,10,12,14$ e 16 gramas de i.a./ha; nos materiais dos solos franco-argiloso e franco-argilo-arenoso, as seguintes doses: $0,50,80,110,140,170$ e 200 gramas de i.a./ha.

O delineamento experimental utilizado fci o inteiramente ao acaso, com 7 tratamentos e 4 repetições.

Após a emergência das plântulas, fez-se o desbaste, deixando-se 4 plântulas em cada copo.

A irrigação das plãntulas foi feita colocandose, quantidade de água suficiente para repor as perdas de peso dos copos. De dois em dois dias as plântulas foram irrigadas com solução de Hoagland modificada (1).

A $50 \mathrm{~cm}$ da superficie dos recipientes foram colocadas lâmpadas fluorescentes, de 40 watts cada uma durante o período das 8 às 18 horas do dia, equivalente a 4.000 lux de intensidade luminosa, para complementar a iluminação nos dias nublados. A temperatura da casa-de-vegetação foi ajustada para os extremos de 25 a $30^{\circ} \mathrm{C}$.

Quatorze dias após o plantio das sementes, as plântulas foram cortadas rente à superfície dos copos, determinando-se o peso de matéria fresca.

As doses de metribuzin, que resultaram em $50 \%$ de inibição do peso fresco das plântulas de pepino foram determinadas, usando gráficos de dosses de metribuzin $\mathrm{x}$ peso das plãntulas de pepino, expresso em percentagem, em relação a testemunha. 


\section{RESULTADOS E DISCUSSÃO}

\section{Lixiviação do metribuzin}

A figura 1 mostra a percentagem de metribuzin lixiviado nas colunas (de 5 a $10 \mathrm{~cm}$ de comprimento) enchidas com materiais dos solos franco-argiloso e franco-argilo-arenoso.

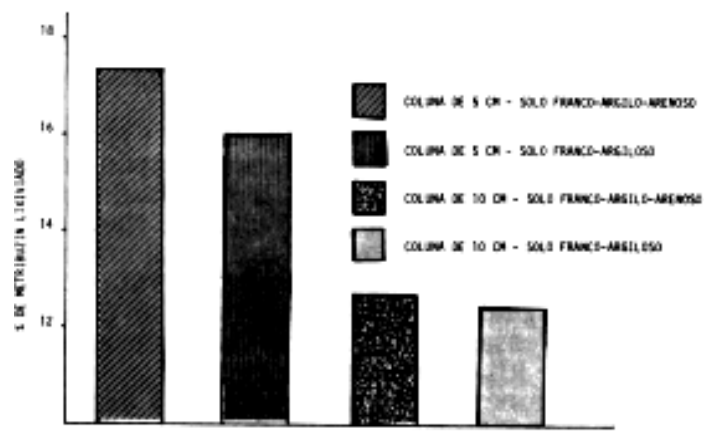

Figura 1. Percentagem de metribuzin lixiviado em colunas de 5 e $10 \mathrm{~cm}$ de comprimento e $7,5 \mathrm{~cm}$ de diâmetro, com a adição de $250 \mathrm{ml}$ de água.

Comparando as percentagens de lixiviação do produto nos dois solos, observa-se que a lixiviação foi ligeiramente maior nos materiais dos solo franco-argilo-arenoso. Esse resultado está relacionado com o menor teor de matéria orgânica desse solo. (quadro 1). Menor teor de matéria orgânica no solo deixa maior quantidade de herbicida em solução e, consequentemente com maior tendência à lixiviação $(9,11,14)$. A figura 1 mostra que a maior diferença na percentagem de lixiviação ocorreu entre as colunas de $5 \mathrm{~cm}$ de comprimento. Esses resultados estão de acordo com os resultados obtidos por Fontes et alii (2), segundo os quais o metribuzin permaneceu livre ho solo, em quantidades maiores na faixa de 0 a $5 \mathrm{~cm}$ de profundiade.

Nas colunas de $10 \mathrm{~cm}$ de comprimento, a diferença entre as percentagens de metribuzin foi proporcional mente menor nos dois solos, o que pode ser explicado pela diluição do produto ao longo da coluna e não saturação dos sítios de adsorção àquela profundidade. de.

A dosagem utilizada de metribuzin (1,0 kg de i.a./ha), não foi suficiente para atravessar a coluna de $15 \mathrm{~cm}$ de comprimento e conseqüentemente, não foi detectada no lixiviado daquela coluna, pelo método dos discos de cotilédones. Inativação do metribuzin

As figuras 2 e 3 mostram o crescimento de plântulas de pepino em areia lavada e nos materiais dos solos francoargilo-arenoso e franco-argiloso, respectivamente, tratados com diferentes doses de metribuzin.

Os I50 (as doses de metribuzin que inibiram $50 \%$ do peso fresco das plântulas de pepino) foram: 10,6, 80 e $130 \mathrm{~g} / \mathrm{ha}$, para areia lavada e para os materiais dos solos franco-argilo-arenoso e franco-argiloso, respectivamente. As diferenças entre os I50 para areia lavada e os I50 para os materiais dos solos de franco-argilo-arenoso e franco-argiloso podem ser considerados como sendo as quantidades do produto inativado por esses materiais.

Vários autores $(9,10,11)$ afirmam que o metribuzin é mais inativado pelos colóides orgânicos do solo que pelos inorgânicos. Segundo Silva (11), dentro do limite de 0 a $8 \%$ de matéria orgânica, há uma relação linear entre o aumento

Quadro 1. Análise química dos materiais dos solos de Capinópolis e de Ponte Nova. viçosa-MG, 1976.

\begin{tabular}{lcc}
\hline & Capinópolis & Ponte Nova \\
\hline pH em água (1: 2,5) & 5,8 & 5,2 \\
Fósforo (P) & $16 \mathrm{ppm}$ & $6 \mathrm{ppm}$ \\
Potássio (K) & $140 \mathrm{ppm}$ & $84 \mathrm{ppm}$ \\
Cálcio + Magnésio eq. mg/100g de solo & 6,70 & 2,70 \\
Alumínio eq. mg/100g de solo & - & 0,10 \\
Matéria orgânica \% & 2,80 & 2,17 \\
\hline \hline
\end{tabular}

* Análises feitas pelo Laboratório de Análises Químicas de Solos da Universidade Federal de Viçosa. 


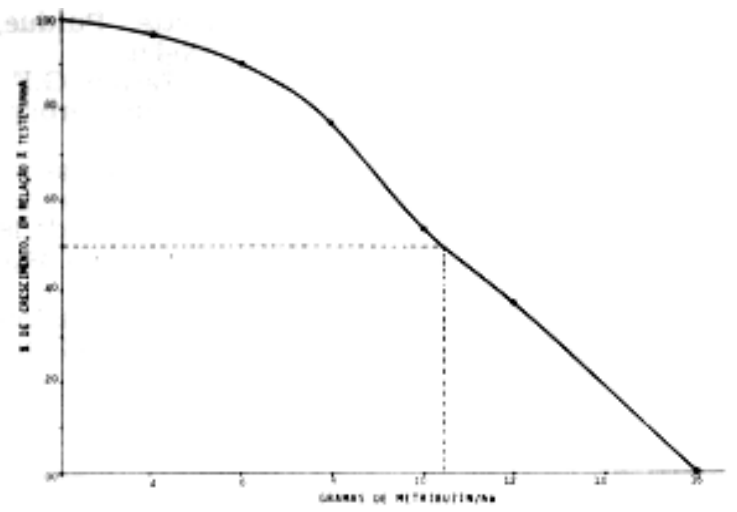

Figura 2. Tolerância de plântulas de pepino ao metribuzin, em areia lavada.

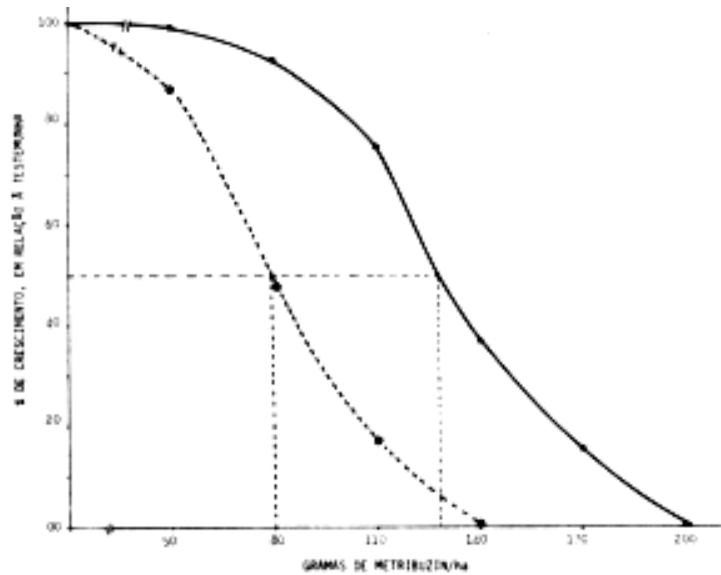

Figura 3. Tolerância das plântulas de pepino ao metribuzin, nos solos franco-argilo-arenoso e franco-argiloso.

da percentagem de matéria orgânica do solo e a percentagem de metribuzin por ela inativada. $\mathrm{O}$ mesmo autor observou que, a partir de 8\% de matéria orgânica no solo inicia-se a interação entre os próprios colóides orgânicos do solo, reduzindo sua taxa de inativação do produto.
Analisando as características químicas e fisicas dos materiais dos solos estudados (quadro 1 e 2) e comparandose com os I $_{50}$ obtidos para os mesmos materiais, observa-se que, a matéria orgânica, foi a maior responsável pelo maior $\mathrm{I}_{50}$ obtido pelo solo franco-argiloso.

O mecanismo pelo qual a matéria orgânica inativa vários herbicidas não é ainda bem conhecido, entretanto, segundo Warren (14), a matéria orgânica, por ser uma substância amorfa, com lacunas de vários tamanhos e formas na sua molécula, é capaz de alojar nessas lacunas moléculas de herbicidas de vários tamanhos e formas, além de apresentar, na sua superfície, diversos grupos ativos que podem adsorver os herbicidas.

\section{LITERATURA CITADA}

1. Epstein, E.. Nutriçáo Mineral das Plantas. Princípios e perspectivas. Ed. Universidade de São Paulo. 314p. 1975.

2. Fontes, L.E.F.; Fernandes, B. \& Silva, J.F. da Movimento e inativação de metribuzin em materiais de dois solos, sob diferentes densidades aparentes. Planta Daninha, Campi. nas, III(1):11-17, 1980.

3. Foster, R. \& Alves, A.. Texto básico de controle químico das plantas daninhas. In: Herbicidas em Agricultura. Capitulo VII. ESALQ Piracicaba. Sảo Paulo. p. 316-363. 1971.

4. Hertwing. K.V.. Manual de herbicidas desfolhantes, dessecantes e fitorreguladores. $1 .^{\mathrm{a}}$ ed. Sảo Paulo SP. Ec. Agronómica Ceres. 1977. 489p.

5. Hichs, R.D.; Addison, D.A.; Edmondson, J.E. Kgaton; McNeill, K.E. \& Webster, H.L., Oryzalin: Weeds Control in no-till soybeans. Proc. So. Weed Sei. Soc. 29:125-132. 1976.

6. Orrego, F.O.Y.. Controle das plantas daninhas na cultura da soja através de misturas e combinaçóes de herbicidas. Comunicado Técnico n. ${ }^{\circ}$ 15. EMPASC. 9p. 1978.

7. Rafael, J.O.V. \& Souza, I.F.. Efeitos fitotoxicos e eflciência de diferentes dosagens de herbicidas em soja. Belo Horizonte. EPA MIG. 1974.

Quadro 2. Análise granulométrica e classificação textural dos solos de Capinópolis e de Ponte Nova. Viçosa-MG, 1976.

\begin{tabular}{lccccc} 
& Areia grossa & Areia fina & Silte & Argila & Chssificaçao textural * \\
\hline Capinópolis & 13 & 24 & 27 & 36 & Iranco-argiloso \\
Ponte Nova & 34 & 21 & 19 & 26 & 1 runcu-argilo-areneso \\
\hline \hline
\end{tabular}

"De acordo com as normas da Sociedade Brasileira de Ciéncias do solo, adotadas pelo Laburatório de Análises Físicas de Solos da Universidade Federal de Viçosa. 
8. Rafael, J.O.V. \& Souza, I.F., Avaliaçâo de herbicidas na cultura da soja (Glycine max (L.) Merr.). Projeto Soja. Relatório anual 74/75. Belo Horizonte. EPAMIG. 1977.

9. Savage, K.E.. Adsortion and mobilidade of metribuzin in soll. Weed Sci. 24(5):525-528, 1976.

10. Schmidt, R.R. Calculations on the herbicidal activity of metribuzin in relation to various soils propieties. Proc. Eur. Weed Res. Coun. Symposium Herbicides, Soil. 24-40. 1973.

11. Silva, J.F. da. Herbicidal Activity and Selec- tivity of metribuxin. Lafayette, Purdue, University, 1975, 58 p. (Tese Ph-D).

12. Sllva, J.F. da; Fadayomi, R.O.; Warren, G.F.. Cotyledon Disc Biossay for Cartain Herbicldes. Weed Sci. 24(3):250-252, 1976.

13. Steindorf, R.H. Controle químico das ervas invasoras na cultura da batata (Solanum tu. berasum (L.)) e estudo sobre a mobilidade de quatro herbicidas. UFV - Viçosa. $1973.44 \mathrm{p}$. (Tese M.S.).

14. Warren, G.F... Action of herbicides in soil affected by organic matter. Weed Today. 4(2):10$-11,1973$. 